\title{
Impact of Co-occurring Dysarthria and Aphasia on Functional Recovery in Post-stroke Patients
}

\author{
Gowun Kim, MD ${ }^{1,2}$, David Min, MD ${ }^{1}$, Eun-ok Lee, SLP ${ }^{1}$, Eun Kyoung Kang, MD, PhD ${ }^{1,2}$
} ${ }^{1}$ Department of Rehabilitation Medicine, Kangwon Regional Cardiocerebrovascular Center, Kangwon National University Hospital,
Chuncheon; ${ }^{2}$ Department of Rehabilitation Medicine, Kangwon National University School of Medicine, Chuncheon, Korea

Objective To elucidate the impact of co-occurring dysarthria and aphasia on functional recovery in post-stroke patients.

Methods The medical records, including results of primary screening tests and secondary definite examinations for language problems, of 130 patients admitted to our institute's Department of Rehabilitation Medicine were retrospectively reviewed. Functional outcomes were assessed longitudinally using the Functional Ambulation Category (FAC), Mini-Mental State Examination-Korean version (MMSE-K), European Quality of Life-5 Dimensions 3-Level version (EQ-5D-3L), the Korean version of the Modified Barthel index (K-MBI), and Motricity Index (MI) of the hemiplegic side.

Results Patients were classified into four groups regarding language function: aphasia only (group A, $\mathrm{n}=9$ ), dysarthria only (group D, $\mathrm{n}=12$ ), aphasia and dysarthria (group $\mathrm{AD}, \mathrm{n}=46$ ), and none (group $\mathrm{N}, \mathrm{n}=55$ ). The initial functional outcome scores in the group AD were significantly poor compared to those of the groups $\mathrm{N}$ and $\mathrm{A}$. Within groups, there were significant improvements in all outcome measurements in the groups $\mathrm{AD}$ and $\mathrm{N}$. A between-group analysis revealed significant improvements in K-MBI for the group AD after adjusting for the initial severity and patient's age compared to other groups.

Conclusion Post-stroke patients suffering from aphasia with dysarthria showed significantly lower initial functional level and relatively wide range of recovery potential in activities of daily living compared to patients without language problems.

Keywords Dysarthria, Aphasia, Stroke, Rehabilitation, Recovery of function

Received February 11, 2016; Accepted June 24, 2016

Corresponding author: Eun Kyoung Kang

Department of Rehabilitation Medicine, Kangwon National University Hospital, 156 Baengnyeong-ro, Chuncheon 24289, Korea. Tel: +82-33-258-9205, Fax: +82-33-258-2146, E-mail: stewardofgod@gmail.com

ORCID: Gowun Kim (http://orcid.org/0000-0002-5694-8111); David Min (http://orcid.org/0000-0002-0956-019X); Eun-ok Lee (http://orcid.org/00000002-2480-9184); Eun Kyoung Kang (http://orcid.org/0000-0001-5315-1361).

() This is an open-access article distributed under the terms of the Creative Commons Attribution Non-Commercial License (http://creativecommons.org/ licenses/by-nc/4.0) which permits unrestricted noncommercial use, distribution, and reproduction in any medium, provided the original work is properly cited. Copyright $\odot 2016$ by Korean Academy of Rehabilitation Medicine 


\section{INTRODUCTION}

Language and speech problems, particularly aphasia and dysarthria, are very common in post-stroke patients. Aphasia refers to a disturbance in verbal communication, the production or understanding of speech, and the ability to read or write due to brain injury, and it is usually secondary to stroke of a left hemispheric lesion [1]. Dysarthria is a motor speech disorder that is often characterized by slurred, slow, weak, imprecise, or uncoordinated speech [2].

Aphasia can not only affect the communication skills and social participation of post-stroke aphasia patients [3], it can also become a stressful burden on caregivers who have the responsibility of caring for aphasic stroke survivors [4]. Dysarthria is also related to physiological functional deterioration, poor self-identity, social and emotional disruptions, and feelings of stigmatization [5]. As a result, both aphasia and dysarthria may influence post-stroke functional recovery and clinical outcomes.

The fact that post-stroke patients often experience a co-occurrence of dysarthria and aphasia highlights the need to consider both conditions when conducting patient evaluations. Trapl et al. [6] reported that $10 \%$ of their acute stroke patients had both dysarthria and aphasia; while Ali et al. [7] reported that the incidence of co- occurring dysarthria and aphasia was as high as $29.6 \%$. However, few studies have reported on the clinical features and functional impact of co-occurring dysarthria and aphasia on post-stroke recovery. Thus, this study aims to elucidate the clinical characteristics and impact of co-occurring dysarthria and aphasia on the functional recovery of post-stroke patients.

\section{MATERIALS AND METHODS}

\section{Subjects}

The medical records of a total of 219 post-stroke patients transferred from the acute stroke center to the Department of Rehabilitation Medicine of Kangwon National University Hospital between December 2013 and July 2015 were retrospectively reviewed. Subjects were excluded if there was a pre-stroke history of language impairment $(\mathrm{n}=1)$; non-stroke neurological condition $(\mathrm{n}=32)$ such as traumatic brain injury, brain tumor, or neurodegenerative disease; or clinical status of medically unstable $(n=2)$. Ultimately, 184 post-stroke patients were included in the primary screening language test (Fig. 1). All patients participated in intensive rehabilitation programs.

Demographic data for the recruited post-stroke patients, including sex, age, stroke type and lesion, hemi-

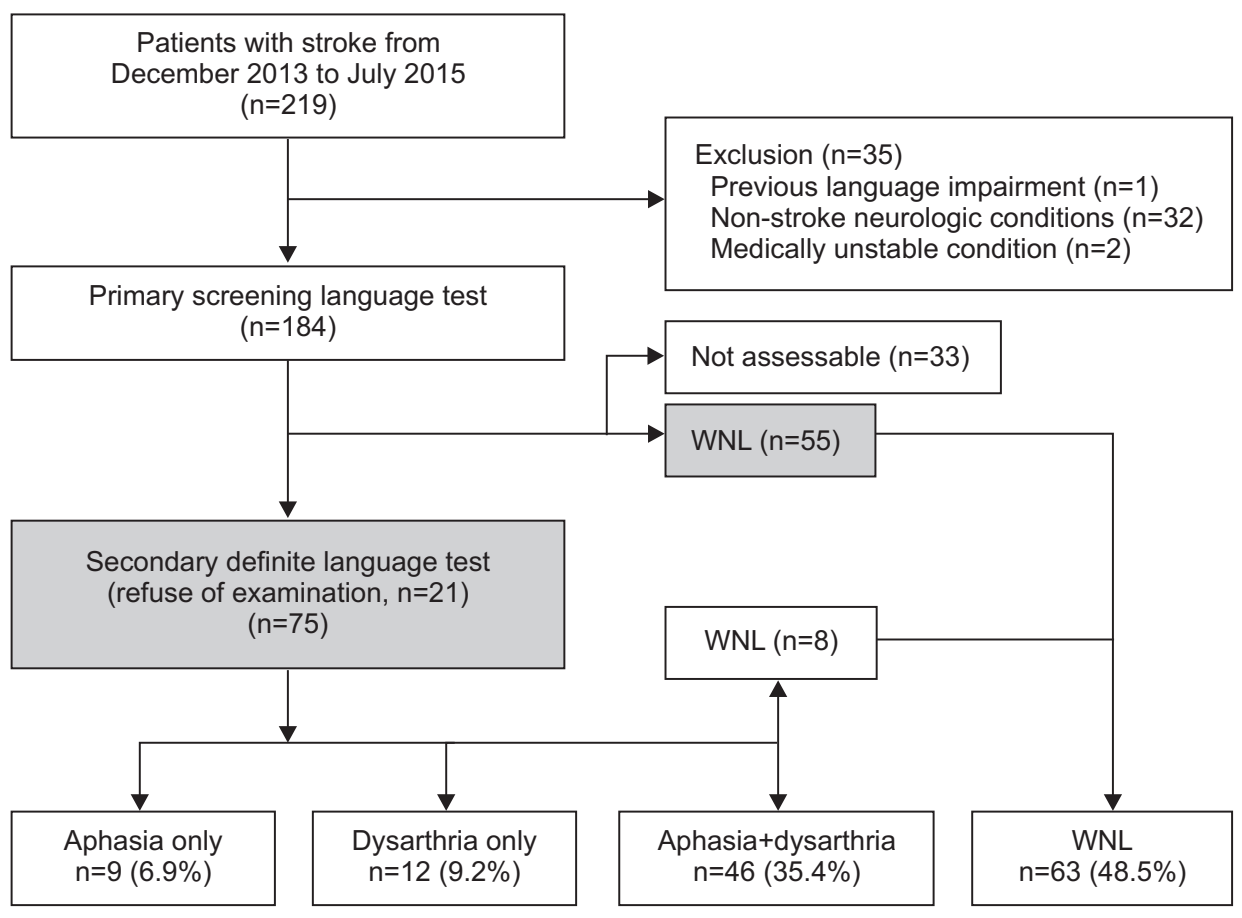

Fig. 1. Inclusion flow chart of the study. WNL, who showed normal language function. 
plegic side, post-onset duration, length of hospital stay, and discharge destination, were collected. A single radiologist classified the stroke lesion locations based on magnetic resonance imaging or computed tomography findings. The study protocol was approved by the Institutional Review Board of Kangwon National University Hospital.

\section{Language and speech evaluations}

All patients were primarily evaluated by a physician on the day of transfer for the presence of aphasia or dysarthria by using a modified screening test from the Korean version of the National Institutes of Health Stroke Scale (NIHSS), which asks the patient to describe the surrounding conditions, name suggested objects, and read or speak some words or sentences [8].

A total of 75 patients with suspected aphasia and/or dysarthria after the primary screening test underwent the secondary definite language test-those who could not perform the secondary definite language test $(n=33)$ or who showed normal language function $(n=55)$ were excluded (Fig. 1). These patients were evaluated by the validated Korean version of the Western Aphasia Battery (K-WAB) [9] and the Speech Mechanism Screening Test (SMST) [10]. A single trained speech-language pathologist performed the K-WAB and SMST for all of the screened post-stroke patients. Finally, secondarily evaluated patients were divided into four groups based on the definite language evaluation results for aphasia and dysarthria: group A, aphasia but no dysarthria; group $\mathrm{D}$, dysarthria but no aphasia; group $\mathrm{AD}$, dysarthria and aphasia; and group N, neither impairment. Patients with normal language function after the primary screening language test were added to group N (Fig. 1).

\section{Functional evaluations}

The Korean version of the Modified Barthel Index (KMBI) [11], Functional Ambulation Category (FAC) [12], Korean version of the Mini-Mental State Examination (MMSE-K) [13], Motricity Index (MI) [14], and European Quality of Life-5 Dimensions 3-Level version (EQ-5D-3L) $[16,17]$ were performed immediately after transfer to and just before discharge from the Department of Rehabilitation Medicine, and the results were retrieved from the medical records to assess the functional outcomes.

\section{Statistical analysis}

The statistical analysis was performed using SPSS for Windows ver. 21.0 (IBM, Armonk, NY, USA). The associations between age, sex, stroke type, hemiplegic side, brain lesion type, and discharge destination among the groups were compared using the $\chi^{2}$ test, and between age and post-onset days by using a Mann-Whitney test. Initial NIHSS, MMSE-K score, EQ-5D-3L index, and MI among the four groups were compared using a one-way analysis of variance (ANOVA) test with least significant differences multiple comparison. The score changes of the KMBI, FAC, EQ-5D-3L, and MMSE-K between admission and discharge among the four groups were analyzed using a one-way ANOVA. We used repeated measures of ANOVA with factor 'Group' (A, D, AD, and N groups) and 'Time' (initial versus discharge) as the repeated measure to compare the effects of 'Group' and 'Time' on functional outcome measures. Percent changes ([discharge score-initial score]/initial score $\times 100$ ) was calculated, and a multivariable linear regression analysis was performed with adjustment by age and initial NIHSS score. Values of $\mathrm{p}<0.05$ were considered to be statistically significant.

\section{RESULTS}

\section{Demographic characteristics of recruited post-stroke patients}

Table 1 shows the demographic and clinical characteristics of 130 post-stroke patients. Patients were classified into four groups according to language function: aphasia only (group $A ; n=9,6.9 \%$ ), dysarthria only (group $D ; n=12$, 9.2\%), aphasia and dysarthria (group $\mathrm{AD} ; \mathrm{n}=46,35.4 \%$ ), and neither (group N; $n=63,48.5 \%$ ). A total of $51.5 \%$ of patients had at least one language impairment. Dysarthria and aphasia occurred in $44.6 \%(n=58)$ and $42.3 \%$ $(\mathrm{n}=55)$ of patients, respectively. Dysarthria and aphasia co-occurred in $35.4 \%$ (group $\mathrm{AD}, \mathrm{n}=46$ ) of patients. By stroke type, infarction was more common than hemorrhage in all groups. However, the proportion of infarction in group $\mathrm{AD}$ was significantly lower than that in groups A, D, and N ( $p<0.05$, Mann-Whitney test). The difference in type of discharge among the groups was statistically significant $\left(\mathrm{p}<0.05, \chi^{2}\right.$ test). The proportion of patients discharged to another institution in group AD (78.3\%) was higher than that of home discharge and higher than those in groups $\mathrm{A}(55.6 \%)$ and $\mathrm{N}(50.8 \%)(\mathrm{p}<0.05)$. Among 
Table 1. Demographic characteristics of recruited post-stroke patients $(\mathrm{n}=130)$

\begin{tabular}{|c|c|c|c|c|c|}
\hline Variable & $\begin{array}{c}\text { Group A } \\
(\mathbf{n}=9)\end{array}$ & $\begin{array}{c}\text { Group D } \\
(n=12)\end{array}$ & $\begin{array}{c}\text { Group AD } \\
(n=46)\end{array}$ & $\begin{array}{c}\text { Group N } \\
(n=63)\end{array}$ & $\begin{array}{c}\text { Total } \\
(n=130)\end{array}$ \\
\hline \multicolumn{6}{|l|}{ Sex } \\
\hline Man & $2(22.2)^{a, b)}$ & $5(41.7)$ & $29(63.0)^{\mathrm{a})}$ & $39(61.9)^{\mathrm{b})}$ & $75(57.7)$ \\
\hline Woman & $7(77.8)$ & $7(58.3)$ & $17(37.0)$ & $24(38.1)$ & $55(42.3)$ \\
\hline Age (yr) & $68.8 \pm 15.7$ & $66.8 \pm 10.7$ & $69.4 \pm 11.3$ & $65.3 \pm 13.1$ & $67.2 \pm 12.3$ \\
\hline$<65$ & $4(44.4)$ & $6(50.0)$ & $12(26.1)$ & $25(39.7)$ & $47(36.2)$ \\
\hline$\geq 65$ & $5(55.6)$ & $6(50.0)$ & $34(73.9)$ & $38(60.3)$ & $83(63.8)$ \\
\hline \multicolumn{6}{|l|}{ Type of stroke } \\
\hline Hemorrhage & $3(33.3)$ & $1(8.3)$ & $11(23.9)$ & $10(15.9)$ & $25(19.2)$ \\
\hline Infarction & $6(66.7)^{a)}$ & $11(91.7)^{\mathrm{c})}$ & $35(76.1)^{\mathrm{a}, \mathrm{c}, \mathrm{d})}$ & $\left.53(84.1)^{d}\right)$ & $105(80.8)$ \\
\hline \multicolumn{6}{|l|}{ Hemiplegic side } \\
\hline Both & - & - & $4(8.7)$ & $3(4.8)$ & $7(5.4)$ \\
\hline Left & $4(44.4)$ & $5(41.7)$ & $22(47.8)$ & $26(41.3)$ & $57(43.8)$ \\
\hline Right & $5(55.6)$ & $7(58.3)$ & $15(32.6)$ & $24(38.1)$ & $51(39.2)$ \\
\hline None & - & - & $5(10.9)$ & $10(15.9)$ & $15(11.5)$ \\
\hline Post-onset days & $12(6.0-21.1)$ & $9(8.0-12.0)$ & $13(9.0-20.5)$ & $10(57.0-74.0)$ & $11(8.0-19.0)$ \\
\hline \multicolumn{6}{|l|}{ Brain lesion } \\
\hline \multicolumn{6}{|l|}{ Cortical lesion } \\
\hline ACA territory & - & - & $3(6.5)$ & $2(3.2)$ & $5(3.8)$ \\
\hline MCA territory & $3(33.3)$ & $5(41.7)$ & $23(50.0)$ & $27(42.9)$ & $58(44.6)$ \\
\hline PCA territory & - & - & $2(4.3)$ & $4(6.3)$ & $6(4.6)$ \\
\hline MCA+ACA territory & $2(22.2)$ & - & - & - & $2(1.5)$ \\
\hline \multicolumn{6}{|l|}{ Subcortical lesion } \\
\hline Basal ganglia & - & $2(16.7)$ & $5(10.9)$ & $6(9.5)$ & $15(11.5)$ \\
\hline Thalamus & $1(11.1)$ & $2(16.7)$ & $2(4.3)$ & $5(7.9)$ & $10(7.7)$ \\
\hline Cerebellum & - & - & $3(6.5)$ & $12(19)$ & $15(11.5)$ \\
\hline Brain stem & - & $3(25.0)$ & $8(17.3)$ & $7(11.1)$ & $19(14.6)$ \\
\hline \multicolumn{6}{|l|}{ Type of discharge } \\
\hline To home & $4(44.4)$ & $7(58.3)$ & $10(21.7)$ & $31(49.2)$ & $55(42.3)$ \\
\hline To other institution & $5(55.6)^{a)}$ & $5(41.7)^{c)}$ & $36(78.3)^{a, c, d)}$ & $32(50.8)^{\mathrm{d})}$ & $75(57.7)$ \\
\hline Length of stay (day) & $31(23.0-42.0)$ & $34.5(28.3-45.3)$ & $40(29.8-49.0)$ & $38(28.0-55.0)$ & $38(28.0-49.0)$ \\
\hline
\end{tabular}

Values are presented as number (\%) or mean \pm standard deviation or median (interquartile range).

Statistically significant differences ${ }^{\mathrm{a})}$ between group $\mathrm{A}$ and group $\mathrm{AD},{ }^{\mathrm{b})}$ between group $\mathrm{A}$ and group $\mathrm{N},{ }^{\mathrm{c}}$ between group $\mathrm{D}$ and group $\mathrm{AD}$, and ${ }^{\mathrm{d})}$ between group $\mathrm{AD}$ and group $\mathrm{N}$ by a $\chi^{2}$ test between paired groups $(\mathrm{p}<0.05)$.

the groups, only group D showed a higher proportion of home discharge compared to discharge to another institution (58.3\% vs. $41.7 \%$, respectively) (Table 1$)$.

Comparison of initial and discharge NIHSS, MMSE-K, EQ-5D-3L, K-MBI, and MI scores by study group

Table 2 shows the initial NIHSS as well as initial and discharge K-MBI, FAC, EQ-5D-3L, MMSE-K and MI scores. The initial NIHSS score $(6.20 \pm 4.15)$ for group AD was higher than that for groups $\mathrm{A}(3.38 \pm 2.39 ; \mathrm{p}<0.05)$ and $\mathrm{N}$ (3.22 $\pm 3.34 ; \mathrm{p}<0.001)$, which his reflective of the severity. The initial MBI score in group AD was the lowest among the four groups, but statistical significance was only seen between groups $\mathrm{AD}$ and $\mathrm{N}(34.17 \pm 26.13$ vs. $58.54 \pm 23.47$, respectively; $\mathrm{p}<0.001$ ). Discharge $\mathrm{MBI}$ in group $\mathrm{AD}$ (52.33 \pm 29.99$)$ was also the lowest among the four groups, and it was lower (statistically significant) than that for group A $(74.11 \pm 20.99 ; \mathrm{p}<0.05)$ and $\mathrm{N}(70.75 \pm 26.04$; 
Table 2. Comparison of initial and discharge NIHSS, MMSE-K, EQ-5D-3L, K-MBI, and MI scores by study group

\begin{tabular}{|c|c|c|c|c|c|c|}
\hline \multicolumn{2}{|c|}{ Initial evaluation } & \multirow{2}{*}{$\begin{array}{c}\text { Group A } \\
3.38 \pm 2.39^{\text {a) }}\end{array}$} & \multirow{2}{*}{$\begin{array}{r}\text { Group D } \\
5.00 \pm 2.72\end{array}$} & \multirow{2}{*}{$\begin{array}{l}\text { Group AD } \\
6.20 \pm 4.15^{\mathrm{a}, \mathrm{d})}\end{array}$} & \multirow{2}{*}{$\begin{array}{c}\text { Group N } \\
3.22 \pm 3.34^{\mathrm{d})}\end{array}$} & \multirow{2}{*}{$\begin{array}{r}\text { p-value } \\
0.001^{*}\end{array}$} \\
\hline NIHSS & Initial & & & & & \\
\hline \multirow[t]{2}{*}{ K-MBI } & Initial & $46.44 \pm 24.99$ & $41.92 \pm 20.95^{\mathrm{c})}$ & $34.17 \pm 26.13^{\mathrm{d})}$ & $58.54 \pm 23.47^{\mathrm{c}, \mathrm{d})}$ & $<0.001^{*}$ \\
\hline & Discharge & $74.11 \pm 20.99^{\mathrm{a})}$ & $62.58 \pm 24.65$ & $52.33 \pm 29.99^{\mathrm{a}, \mathrm{d})}$ & $70.75 \pm 26.04^{\mathrm{d})}$ & $0.005^{*}$ \\
\hline \multirow[t]{2}{*}{ FAC } & Initial & $2.22 \pm 1.72^{\mathrm{d})}$ & $1.33 \pm 1.23^{\mathrm{b})}$ & $1.11 \pm 1.27^{\mathrm{a}, \mathrm{c})}$ & $2.40 \pm 1.51^{\mathrm{b}, \mathrm{c})}$ & $<0.001^{*}$ \\
\hline & Discharge & $3.33 \pm 1.87$ & $3.25 \pm 1.91$ & $2.24 \pm 1.77^{\mathrm{d})}$ & $3.33 \pm 1.48^{\mathrm{d})}$ & $0.007^{*}$ \\
\hline \multirow[t]{2}{*}{ EQ-5D-3L } & Initial & $0.3420 \pm 0.4076$ & $0.3099 \pm 0.3037$ & $0.2293 \pm 0.3737$ & $0.3885 \pm 0.3262$ & 0.153 \\
\hline & Discharge & $0.5056 \pm 0.4105$ & $0.5336 \pm 0.3274$ & $0.3513 \pm 0.3717^{\mathrm{d})}$ & $0.5003 \pm 0.3181^{\mathrm{d})}$ & 0.132 \\
\hline \multirow[t]{2}{*}{ MMSE-K } & Initial & $21.00 \pm 4.95$ & $21.58 \pm 4.52^{\mathrm{b})}$ & $16.39 \pm 7.60^{\mathrm{b}, \mathrm{d})}$ & $21.92 \pm 7.63^{\mathrm{d})}$ & $0.001^{*}$ \\
\hline & Discharge & $24.33 \pm 3.61^{\text {a) }}$ & $24.33 \pm 3.53^{\mathrm{b})}$ & $19.33 \pm 7.56^{\mathrm{a}, \mathrm{b}, \mathrm{d})}$ & $23.97 \pm 6.63^{\mathrm{d})}$ & $0.002^{*}$ \\
\hline \multirow[t]{2}{*}{ MI } & Initial & $69.78 \pm 24.86^{\mathrm{a})}$ & $62.04 \pm 28.17$ & $47.17 \pm 36.52^{\mathrm{a}, \mathrm{d})}$ & $72.90 \pm 27.39^{\mathrm{d})}$ & $<0.001^{*}$ \\
\hline & Discharge & $79.72 \pm 20.86^{\text {a) }}$ & $74.29 \pm 33.26$ & $58.04 \pm 34.00^{\mathrm{a}, \mathrm{d})}$ & $80.65 \pm 25.77^{\mathrm{d})}$ & $0.001^{*}$ \\
\hline
\end{tabular}

Values are presented as mean \pm standard deviation.

K-NIHSS, Korean version of National Institutes of Health Stroke Scale; FAC, Functional Ambulation Category; MMSEK, Korean version of Mini-Mental State Examination; EQ-5D-3L, European Quality of Life-5 Dimensions 3 Level; KMBI, Korean version of Modified Barthel Index; MI, Motricity Index of hemiplegic side.

${ }^{*} \mathrm{p}<0.05$, statistically significant differences ${ }^{\mathrm{a})}$ between group $\mathrm{A}$ and group $\mathrm{AD},{ }^{\text {b) }}$ between group $\mathrm{D}$ and group $\mathrm{AD},{ }^{\mathrm{c})}$ between group $\mathrm{D}$ and group $\mathrm{N}$, and ${ }^{\mathrm{d})}$ between group $\mathrm{AD}$ and group $\mathrm{N}$ based on one-way ANOVA test with LSD multiple comparison.

$\mathrm{p}<0.05)$. The initial FAC score of group AD $(1.11 \pm 1.27)$ was lower than that for groups $\mathrm{A}(2.22 \pm 1.72 ; \mathrm{p}<0.05)$ and $\mathrm{N}(2.40 \pm 1.51 ; \mathrm{p}<0.001)$. Similarly, the discharge FAC score for group $\mathrm{AD}$ was the lowest among the four groups, but statistical significance was only seen between groups $\mathrm{AD}$ and $\mathrm{N}(2.24 \pm 1.77$ vs. $3.33 \pm 1.48 ; \mathrm{p}=0.001)$. The initial MMSE-K score of group AD (16.39 \pm 7.60$)$ was lower than those of groups $\mathrm{D}(21.58 \pm 4.52 ; \mathrm{p}<0.05)$ and $\mathrm{N}(21.92 \pm 7.63$; $\mathrm{p}<0.001)$. The discharge MMSE-K score in group AD was the lowest among the four groups, and it was statistically significant $(\mathrm{p}=0.002)$. The initial and discharge MI score of group AD was lower than those of groups $A(p<0.05)$ and $\mathrm{N}(\mathrm{p}<0.001)$. Moreover, the EQ-5D-3L index showed no significant differences (Table 2).

Comparison of K-MBI, FAC, EQ-5D-3L, MMSE-K, and MI scores at the initial and discharge times

The repeated measures of ANOVA revealed significant 'Time' effects on all functional scales between the initial and discharge times $(\mathrm{p}<0.001)$. We detected a significant 'Group' effect on K-MBI $(\mathrm{F}=6.890, \mathrm{p}<0.001)$ and FAC ( $\mathrm{F}=6.533, \mathrm{p}=0.001)$, as well as Time $\times$ Group interactions (K-MBI: $\mathrm{F}=3.638, \mathrm{p}=0.015$; FAC: $\mathrm{F}=2.187, \mathrm{p}<0.001$ ), showing statistical significance between group $\mathrm{AD}$ and group $\mathrm{N}$ based on an LSD multiple comparison $(\mathrm{p}<0.05)$. There are no group effects and Time $\times$ Group interaction in EQ-
5D-3L. In addition, there were significant Group effects in MMSE-K ( F=5.900, $\mathrm{p}=0.001)$ and $\mathrm{MI}(\mathrm{F}=6.220, \mathrm{p}=0.001)$ (Table 3).

Result of multivariable linear regression analysis to show the functional improvements regarding the initial severity and age

A multivariate linear regression analysis adjusted by the initial NIHSS score and age showed that the improvements in K-MBI was independent to the initial severity and age $(p=0.015)$, while the percent changes of FAC, MMSE, EQ-5D-3L, and MI did not show statistical significance (Table 4).

\section{DISCUSSION}

This study aimed to show the clinical characteristics and impact of co-occurring dysarthria and aphasia on post-stroke functional outcomes. Our findings indicate that the presence of co-occurring aphasia and dysarthria in post-stroke patients is related to poor neurological and functional status as well as poor functional recovery in post-stroke patients.

Ali et al. [7] respectively examined recovery and functional outcomes in post-stroke patients with aphasia or dysarthria and reported that persistent aphasia at 3 
Table 3. Comparison between initial and discharge K-MBI, FAC, EQ-5D-3L, MMSE-K, and MI scores

\begin{tabular}{|c|c|c|c|c|c|c|}
\hline & \multicolumn{2}{|c|}{ Group } & \multicolumn{2}{|c|}{ Time } & \multicolumn{2}{|c|}{ Time $\times$ Group } \\
\hline & $\mathbf{F}$ & p-value & $\mathbf{F}$ & p-value & $\mathbf{F}$ & p-value \\
\hline K-MBI & 6.890 & $<0.001^{\mathrm{c})}$ & 111.887 & $<0.001$ & 3.638 & 0.015 \\
\hline FAC & 6.533 & $0.001^{a, c)}$ & 75.459 & $<0.001$ & 2.187 & $<0.001$ \\
\hline EQ-5D-3L & 1.980 & $0.121^{c)}$ & 29.554 & $<0.001$ & 0.831 & 0.479 \\
\hline MMSE-K & 5.900 & $0.001^{a, b, c)}$ & 25.147 & $<0.001$ & 0.454 & 0.715 \\
\hline MI & 6.220 & $0.001^{\mathrm{a}, \mathrm{c})}$ & 38.667 & $<0.001$ & 0.668 & 0.573 \\
\hline
\end{tabular}

MMSE-K, Korean version of Mini-Mental State Examination; FAC, Functional Ambulation Category; EQ-5D-3L, European Quality of Life-5 Dimensions 3 Level; K-MBI, Korean version of Modified Barthel Index; MI, Motricity Index of hemiplegic side.

Statistically significant differences ${ }^{\text {a) }}$ between group A and group $\mathrm{AD}$, ${ }^{\mathrm{b}}$ between group $\mathrm{D}$ and group $\mathrm{AD}$, and ${ }^{\mathrm{c})}$ between group $\mathrm{AD}$ and group $\mathrm{N}$ based on repeated measures ANOVA test with LSD multiple comparison $(\mathrm{p}<0.05)$.

Table 4. Result of multivariable linear regression analysis to show functional improvements regarding the initial severity and age

\begin{tabular}{lccccc}
\hline \% change & Group A & Group D & Group AD & Group N & p-value \\
\hline K-MBI (\%) & $93.0 \pm 87.6$ & $64.8 \pm 80.4$ & $102.5 \pm 165.4$ & $24.3 \pm 33.9$ & $0.015^{*}$ \\
\hline FAC (\%) & $89.3 \pm 55.6$ & $213.9 \pm 53.2$ & $84.0 \pm 19.4$ & $64.4 \pm 13.1$ & 0.157 \\
EQ-5D-3L (\%) & $124.0 \pm 354.3$ & $334.4 \pm 587.5$ & $-66.4 \pm 359.4$ & $40.1 \pm 188.4$ & 0.096 \\
\hline MMSE-K (\%) & $21.3 \pm 33.3$ & $19.2 \pm 42.8$ & $34.5 \pm 69.0$ & $29.9 \pm 170.9$ & 0.255 \\
\hline MI (\%) & $22.5 \pm 29.9$ & $18.2 \pm 15.7$ & $349.9 \pm 1296.1$ & $50.1 \pm 283.0$ & 0.950 \\
\hline
\end{tabular}

Values are presented as mean \pm standard deviation.

K-MBI, Korean version of Modified Barthel Index; FAC, Functional Ambulation Category; EQ-5D-3L, European Quality of Life-5 Dimensions 3 Level; MMSE-K, Korean version of Mini-Mental State Examination; MI, Motricity Index of hemiplegic side.

${ }^{*} \mathrm{p}<0.05$, multivariable linear regression analysis was performed with adjustment by each initial NIHSS score and age.

months was related to a poor modified Rankin Scale. However, patients classified in the aphasia or dysarthria groups may have a combination of dysarthria and aphasia in some cases, so the functional recovery of aphasia-/ dysarthria-only patients may differ from that of aphasia and dysarthria patients despite being classified into the same group. Thus, this study classified post-stroke language disturbance groups without overlap to show the impact of the co-occurrence of aphasia and dysarthria.

To date, post-stroke aphasia and dysarthria have only been regarded as independent parameters of functional status. Aphasia affects activities of daily living (ADLs) [18] and can result in a poor quality of life [19]. Akosile et al. [20] reported that stroke survivors with aphasia had had poor gait quality and physical functioning, as measured by the Stroke Impact Scale-16, than stroke survivors without aphasia. Post-stroke patients with dysarthria showed a much lower Barthel Index at 8 weeks post-stroke than predicted (6 vs. 15.5) [21] as well as poor quality of life related to self-esteem and limited social relationships [5]. However, there are few prior reports on whether there were differences in ambulation status or motor power between patients with and without language problems. Thus, this study investigated additional MI and FAC as functional outcome measures, and showed significantly better initial and discharge levels in group $\mathrm{N}$ compared to group $\mathrm{AD}$ ( $\mathrm{p}<0.05$ by LSD multiple comparison).

Post-stroke language impairments are more common in post-stroke patients with co-occurring aphasia and dysarthria than in those with aphasia or dysarthria only. Post-stroke patients with co-occurring dysarthria and aphasia have higher initial NIHSS scores and lower MMSE-K, EQ-5D-3L index, K-MBI, and MI scores, reflecting a more severe post-stroke status, poor cognitive function, poor quality of life, dependence for ADLs, and poor motor power and trunk control function $[8,11,13-17]$ 
compared to post-stroke patients with aphasia only, poststroke patients with dysarthria only, and controls with normal language function.

In addition, follow-up post-stroke recovery differed among the post-stroke language groups, reflecting the profound impact of co-occurring aphasia and dysarthria on post-stroke recovery. The rate of spontaneous poststroke neurological recovery is the highest during the first 3 months [22], and the rate is affected by several confounders. In this regard, aphasia or dysarthria were associated with poor functional recovery, increased mortality, and depression $[1,7,23]$. Ali et al. [7] reported that aphasia at baseline and at 3 months as well as persistent dysarthria at 3 months were significantly associated with poorer modified Rankin Scale at 3 months. However, cooccurring aphasia and dysarthria at baseline and persistent impairment at 3 months were not associated with a poorer modified Rankin Scale score at 3 months.

In this study, co-occurring dysarthria and aphasia are observed to affect the recovery of ADLs, quality of life, cognitive function, motor power, and ambulation status. In addition, differences in improvements of functional outcomes significantly affected ADLs. Functional recovery in post-stroke patients can vary according to the presence of dysarthria and/or aphasia. The improvements in ADLs of patients were different for each group when the effects of the initial severity and patients' age were eliminated.

In our study, the improvement in ADLs of patients with co-occurring dysarthria and aphasia was relatively higher than those of patients in other groups. For group $\mathrm{AD}$, the initial functional status was poor and the K-MBI score at discharge was lower than that for the other groups, and this was considered to be a result of the potential wide range of improvement in patients with co-occurring dysarthria and aphasia.

Our study has some limitations. First, some of the groups were too small to show sufficient statistical power. There were 9 and 12 patients in group A and D each. Second, the study design, consisted of a retrospective chart review and may include selection bias. Additionally, all subjects were discharged from the department of rehabilitation medicine. Finally, patients with rehabilitation needs who were admitted to the inpatient rehabilitation unit were included here. However, some other patients with mild dysarthria and aphasia may have been treated on an outpatient basis only. Further studies to compensate for these limitations may be needed.

In conclusion, post-stroke patients with co-occurring aphasia and dysarthria had a more severe stroke, poorer cognitive function, worse quality of life, required more support to perform ADLs, and had reduced motor power, while showing greater potential range of functional improvements, especially in ADLs. If post-stroke patients present aphasia and dysarthria at the initial language assessment, the rehabilitation plan should include an additional strategy to improve communication skills. The identification and characterization of language and speech problems in post-stroke patients provides valuable prognostic information and aids in planning adequate rehabilitation programs.

\section{CONFLICT OF INTEREST}

No potential conflict of interest relevant to this article was reported.

\section{REFERENCES}

1. Wade DT, Hewer RL, David RM, Enderby PM. Aphasia after stroke: natural history and associated deficits. J Neurol Neurosurg Psychiatry 1986;49:11-6.

2. Simm WA, Roberts PE, Joyce MJ. Dysarthric speech measures for use in evidence-based speech therapy. In: Clarkson J, Langdon P, Robinson P, editors. Designing accessible technology. London: Springer; 2006. p. 155-64.

3. Davidson B, Howe T, Worrall L, Hickson L, Togher L. Social participation for older people with aphasia: the impact of communication disability on friendships. Top Stroke Rehabil 2008;15:325-40.

4. Bakas T, Kroenke K, Plue LD, Perkins SM, Williams LS. Outcomes among family caregivers of aphasic versus nonaphasic stroke survivors. Rehabil Nurs 2006;31:3342.

5. Dickson S, Barbour RS, Brady M, Clark AM, Paton G. Patients' experiences of disruptions associated with post-stroke dysarthria. Int J Lang Commun Disord 2008;43:135-53.

6. Trapl M, Eckhardt R, Bosak P, Brainin M. Early recognition of speech and speech-associated disorders after acute stroke. Wien Med Wochenschr 2004;154:571- 
6.

7. Ali M, Lyden P, Brady M. Aphasia and dysarthria in acute stroke: recovery and functional outcome. Int J Stroke 2015;10:400-6.

8. Lee KM, Jang YH, Kim YH, Moon SK, Park JH, Park SW, et al. Reliability and validity of Korean version of National Institutes of Health Stroke Scale: multi-center study. J Korean Acad Rehabil Med 2004;28:422-35.

9. Kim H, Na DL. Paradise Korean version of the Western Aphasia Battery (K-WAB). Seoul: Paradise Welfare Foundation, Institute for Children with Disabilities; 2001.

10. Shin MJ, Lee SB, Lee SY. Speech mechanism screening test (SMST). Seoul: Hakjisa; 2010.

11. Jung HY, Park BK, Shin HS, Kang YK, Pyun SB, Paik NJ, et al. Development of the Korean version of Modified Barthel Index (K-MBI): multi-center study for subjects with stroke. J Korean Acad Rehabil Med 2007;31:28397.

12. Mehrholz J, Wagner K, Rutte K, Meissner D, Pohl M. Predictive validity and responsiveness of the functional ambulation category in hemiparetic patients after stroke. Arch Phys Med Rehabil 2007;88:1314-9.

13. Park JH, Kwon YC. Standardization of Korean version of the Mini-Mental State Examination (MMSE-K) for use in the elderly. Part II: Diagnostic validity. J Korean Neuropsychiatr Assoc 1989;28:508-13.

14. Shah S, Vanclay F, Cooper B. Predicting discharge status at commencement of stroke rehabilitation. Stroke 1989;20:766-9.

15. Franchignoni FP, Tesio L, Ricupero C, Martino MT.
Trunk control test as an early predictor of stroke rehabilitation outcome. Stroke 1997;28:1382-5.

16. Jo MW, Yun SC, Lee SI. Estimating quality weights for EQ-5D health states with the time trade-off method in South Korea. Value Health 2008;11:1186-9.

17. Golicki D, Niewada M, Buczek J, Karlinska A, Kobayashi A, Janssen MF, et al. Validity of EQ-5D-5L in stroke. Qual Life Res 2015;24:845-50.

18. Dickey L, Kagan A, Lindsay MP, Fang J, Rowland A, Black S. Incidence and profile of inpatient strokeinduced aphasia in Ontario, Canada. Arch Phys Med Rehabil 2010;91:196-202.

19. Jerome D, Dehail P, Daviet JC, Lamothe G, De Seze MP, Orgogozo JM, et al. Stroke in under-75-year-olds: expectations, concerns and needs. Ann Phys Rehabil Med 2009;52:525-37.

20. Akosile CO, Adegoke BO, Raji NO, Anyanwu CC, Orji GC. Gait quality and physical functioning of stroke survivors with and without aphasia. Hong Kong Physiother J 2013;31:25-9.

21. Tilling K, Sterne JA, Rudd AG, Glass TA, Wityk RJ, Wolfe CD. A new method for predicting recovery after stroke. Stroke 2001;32:2867-73.

22. Demeurisse G, Demol O, Derouck M, de Beuckelaer R, Coekaerts MJ, Capon A. Quantitative study of the rate of recovery from aphasia due to ischemic stroke. Stroke 1980;11:455-8.

23. Laska AC, Hellblom A, Murray V, Kahan T, Von Arbin M. Aphasia in acute stroke and relation to outcome. J Intern Med 2001;249:413-22. 